\title{
Thermomechanical Buckling Analysis of the E\&P-FGM Beams Integrated by Nanocomposite Supports Immersed in a Hygrothermal Environment
}

\author{
Mohammad Khorasani ${ }^{1}$, Luca Lampani ${ }^{2}$, Rossana Dimitri ${ }^{3}\left[\right.$ and Francesco Tornabene ${ }^{3, *}$ (D) \\ 1 Department of Basic and Applied Sciences for Engineering, Sapienza University, 00185 Rome, Italy; \\ khorasani.1829460@studenti.uniroma1.it \\ 2 Department of Mechanical and Aerospace Engineering, Sapienza University, 00184 Rome, Italy; \\ luca.lampani@uniroma1.it \\ 3 Department of Innovation Engineering, Università del Salento, 73100 Lecce, Italy; \\ rossana.dimitri@unisalento.it \\ * Correspondence: francesco.tornabene@unisalento.it; Tel./Fax: +39-08-3229-7275
}

Citation: Khorasani, M.; Lampani, L.; Dimitri, R.; Tornabene, F.

Thermomechanical Buckling Analysis of the E\&P-FGM Beams Integrated by Nanocomposite Supports Immersed in a Hygrothermal Environment. Molecules 2021, 26, 6594. https:// doi.org/10.3390/molecules26216594

Academic Editor: Baljinder Kandola

Received: 14 October 2021

Accepted: 27 October 2021

Published: 30 October 2021

Publisher's Note: MDPI stays neutral with regard to jurisdictional claims in published maps and institutional affiliations.

Copyright: (c) 2021 by the authors. Licensee MDPI, Basel, Switzerland. This article is an open access article distributed under the terms and conditions of the Creative Commons Attribution (CC BY) license (https:/ / creativecommons.org/licenses/by/ $4.0 /)$.

\begin{abstract}
Due to the widespread use of sandwich structures in many industries and the importance of understanding their mechanical behavior, this paper studies the thermomechanical buckling behavior of sandwich beams with a functionally graded material (FGM) middle layer and two composite external layers. Both composite skins are made of Poly(methyl methacrylate) (PMMA) reinforced by carbon-nano-tubes (CNTs). The properties of the FGM core are predicted through an exponential-law and power-law theory (E\&P), whereas an Eshelby-Mori-Tanaka (EMT) formulation is applied to capture the mechanical properties of the external layers. Moreover, different high-order displacement fields are combined with a virtual displacement approach to derive the governing equations of the problem, here solved analytically based on a Navier-type approximation. A parametric study is performed to check for the impact of different core materials and CNT concentrations inside the PMMA on the overall response of beams resting on a Pasternak substrate and subjected to a hygrothermal loading. This means that the sensitivity analysis accounts for different displacement fields, hygrothermal environments, and FGM theories, as a novel aspect of the present work. Our results could be replicated in a computational sense, and could be useful for design purposes in aerospace industries to increase the tolerance of target productions, such as aircraft bodies.
\end{abstract}

Keywords: CNTs; FGMs; high-order shear deformation theories; hygrothermal environment; thermomechanical buckling; sandwich beams

\section{Introduction}

FGM-based structures serve as bi-phase beams, plates and shells whose properties vary across their thickness or length continuously. Over the last century, FGMs have increasingly attracted the interest of the scientific community for their use in different high-tech industries due to their outstanding mechanical properties compared to singlephase materials and structures. Some natural types of FGMs are visible, such as bamboo trees, teeth, bones, and human skin, which have evolved to meet a specific requirement in humans and their environment. For the first time, Shen and Bever [1] considered graded material composites, despite their limited knowledge and a general lack of sophisticated fabrication equipment. Subsequently, Japanese scientists in 1984 [2] applied this technique to an aerospace project, due to their necessity to have a $10 \mathrm{~mm}$ thickness thermal barrier with an internal and external temperature of $1000 \mathrm{~K}$ and $2000 \mathrm{~K}$, respectively. Fu et al. [3] also studied the thermoacoustic response of a porous FGM cylindrical plate with a random distribution of pores. Moreover, Duc and Cong [4] studied the vibrational behavior of FGM plates using a Runge-Kutta method, whose model was affected by thermomechanical 
coupled loading conditions. In another work, Shen [5] studied the thermomechanical post-buckling behavior of a simply-supported FGM plate equipped with piezoelectric fiber-reinforced composite patches for sensors, actuators, transducers and active damping devices. Zenkour [6] studied the static deflection response of an FGM plate in a hygrothermal environment, while discussing the response sensitivity to different environmental conditions. Transient analysis of porous FGM plates was also considered by Van et al. [7] in a nonlinear domain subjected to a coupled hygrothermal and mechanical loading condition. A post-buckling study of sandwich plates with FGM skins was performed by Kiani and Eslami [8] in a numerical sense, focusing on the effect of the power-law index, foundation parameters and imperfections of the overall response. In addition to the theoretical studies, many researchers have experimentally investigated the vibration and damping properties of nanoparticle-reinforced composite materials [9-12].

Besides FGMs, other composite nanomaterials have attracted the interest of engineering device production, with the rapid development of various analytical and computational models designed to simulate their behavior even in a nonlocal sense. In this context, Arshid et al. [13] studied the dynamic and static behavior of annular FG graphene nanoplatelets (FG-GNPs) reinforced nanocomposite with porosities, and applied modified strain gradient theory (MSGT) to account for size-dependent effects. In another work, Foroutan et al. [14] surveyed the nonlinear buckling and vibration behavior of imperfect FG carbon nanotubes reinforced composite (FG-CNTRC) cylindrical shells in a hygrothermal environment. Similarly, Arshid et al. [15] applied a 3D plate theory to study the vibrations of sandwich structures with a honeycomb core and GNP-reinforced epoxy face sheets, as commonly found in many electric devices. Safaei [16] developed a generalized vibration model including the possible presence of porosity within sandwich structures (both in core and skins) immersed in a Pasternak foundation. Among the recent scientific literature, several theoretical and numerical methods have been proposed to solve complicated structural problems, involving advanced composite materials. Moradi-Dastjerdi et al. [17] applied a higher-order theory and the Eshelby-Mori-Tanaka (EMT) approach to assess the buckling behavior of a sandwich plate made of a CNTRC porous core with external piezoelectric face sheets, while assuming different CNTs' agglomerations within the material. In a similar direction, the authors of Refs. [18,19] proposed a refined higher-order theory to evaluate the CNTs' agglomeration impact on the vibration control and stiffness of nanocomposite sandwich beams, respectively. In addition, further efforts in this direction have been performed by other scholars [20-49].

Motivated by the aforementioned studies, this paper aims to further contribute to the thermomechanical response of sandwich beams including an exponential-law / powerlaw-based functionally graded core (E\&P-FGC) integrated by two CNTRC layers. A unified framework was originally proposed to account for different high-order kinematic assumptions for the systematic study of sandwich structures resting on an elastic Pasternak substrate, under coupled hygrothermal loading conditions. The governing equations of the problem are determined from the virtual displacement principle, accounting for various beam theories and CNTs' agglomeration effects. A Navier-type procedure was, thus, proposed to solve the problem analytically, whose results, based on different E\&P-FGM relations and thermomechanical conditions could be very useful for further computational investigations on this topic, even from a practical design standpoint.

\section{Analytical Model}

Let us consider a three-layer sandwich beam with length $a$ and thickness $h$. As shown in Figure 1, the total thickness is the assemblage of an FGC, and two external (top and bottom) CNTRC skins, with thickness $h_{c}, h_{t}$, and $h_{b}$, respectively. The model is referred to as the cartesian coordinate system $(x, y, z)$, and it is located at the midplane of the model, as depicted in Figure 1. The whole structure is embedded in an elastic Pasternak substrate, and it is subjected to a variable hygrothermal surrounding condition. 


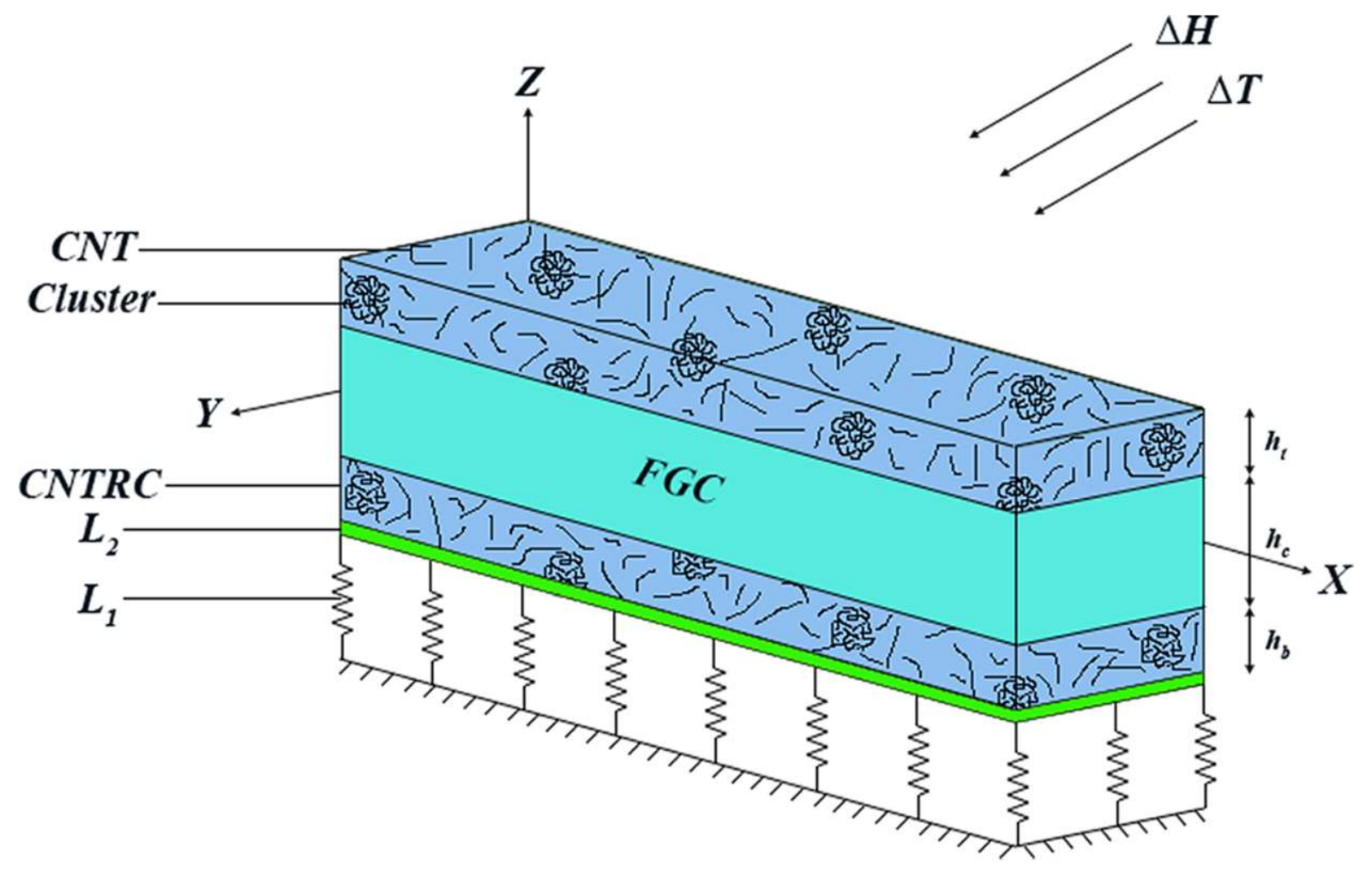

Figure 1. Sandwich beam model.

For this sandwich structure, we propose and compare a thermomechanical model based on four different kinematic assumptions, namely, the third-order shear deformation theory (TSDT), the hyperbolic shear deformation theory (HSDT), the sinusoidal shear deformation theory (SSDT) and the exponential shear deformation theory (ESDT). Based on these kinematic assumptions, the displacement field for an arbitrary point in the mid surface is defined as $[20,21]$.

$$
\begin{aligned}
& U(x, z)=u(x)-z \frac{\partial w(x)}{\partial x}+\left[\begin{array}{cc}
z-\frac{4 z^{3}}{3 h^{2}} & \text { TSDT } \\
h \sinh \left(\frac{z}{h}\right)-z \cosh \left(\frac{1}{2}\right) & H S D T \\
\frac{h}{\pi} \sin \left(\frac{\pi z}{h}\right) & S S D T \\
z \exp \left(-2\left(\frac{z}{h}\right)^{2}\right) & E S D T
\end{array}\right] u_{1}(x), \\
& V(x, z)=0 \text {, } \\
& W(x, z)=w(x)
\end{aligned}
$$

where $u$ and $w$ refer to the longitudinal and transverse displacement components of the mid surface. For simplicity reasons, Equation (1) can be rewritten in a more compact notation by introducing a general function $Q(z)$ to define the terms in the square brackets, depending on the selected kinematic theory. Thus, by simply changing the definition of $Q(z)$, we are able to switch among different displacement assumptions.

The kinematic relations between the strain and displacement fields are, thus, expressed as [22]:

$$
\begin{gathered}
\varepsilon_{x x}^{c, t, b}=\frac{\partial U}{\partial x} \\
\gamma_{x z}^{c, t, b}=\frac{\partial U}{\partial z}+\frac{\partial W}{\partial x}
\end{gathered}
$$

where superscripts $c, t$, and $b$ refer to the core, top, and bottom layer.

For every single layer of the sandwich structure, we refer to the following constitutive relations $[23,24]$ :

$$
\begin{gathered}
\sigma_{x x}^{c, t, b}=A_{11}^{c, t, b} \varepsilon_{x x}-\alpha_{x x}^{c, t, b} \Delta T-\beta_{x x}^{c, t, b} \Delta H, \\
\tau_{x z}^{c, t, b}=A_{55}^{c, t, b} \gamma_{x z}
\end{gathered}
$$


where $A$ refers to the elastic constants, $\beta$ and $\alpha$ denote the moisture and thermal expansion coefficients, respectively, $\Delta T$ and $\Delta H$ stand for the thermal and moisture variation, respectively, defined as $\Delta T=T(z)-T_{0}$ and $\Delta H=H(z)-H_{0}$. Moreover, $T_{0}$ and $H_{0}$ denote the ambient temperature and moisture, here kept equal to $293 \mathrm{~K}$ and $0.1 \mathrm{wt} \% \mathrm{H}_{2} \mathrm{O}$, respectively. Furthermore, $T(z)$ and $H(z)$ represent a linear temperature and moisture variation across the thickness direction of the beam [25]:

$$
\begin{aligned}
& T(z)=T_{b}+\Delta T_{t b}\left(\frac{h+2 z}{2 h}\right), \\
& H(z)=H_{b}+\Delta H_{t b}\left(\frac{h+2 z}{2 h}\right)
\end{aligned}
$$

where subscripts $t$ and $b$ refer to the top and bottom surface of the model. At the same time, $\Delta T_{t b}$ and $\Delta H_{t b}$ stand for the thermal and moisture variation between the top and bottom sides, namely, $\Delta T_{t b}=T_{t}-T_{b}$ and $\Delta H_{t b}=H_{t}-H_{b}$.

The core layer of the selected sandwich beam is made up of FGMs, which means that the top and bottom surfaces of the FGC are made of pure ceramic and pure metal, whereas from the bottom to the top surfaces, the volume fraction of the metal and ceramic phases vary, keeping fixed $V_{c}+V_{m}=1$. In what follows, we consider two different variations of material properties throughout the thickness of the FGC, evaluated here comparatively for their impact on the thermomechanical buckling behavior of the whole structure. Based on the P-FGC and E-FGC, the mechanical properties of the FGC are defined as:

$$
\begin{array}{ll}
J^{\mathcal{C}}(z)=J_{m} \exp \left(\log \left(\frac{J_{c}}{J_{m}}\right)\left(\frac{h_{c}+2 z}{2 h_{c}}\right)\right) & E-F G C \\
J^{\mathcal{C}}(z)=\left(J_{c}-J_{m}\right)\left(\frac{h_{c}+2 z}{2 h_{c}}\right)^{S}+J_{m}, & P-F G C
\end{array}
$$

where subscripts $c$ and $m$ denote the ceramic and metallic properties, respectively. Moreover, $J$ is a general notation that defines the arbitrary mechanical property, as the elasticity modulus $E$, Poisson's ratio $\nu$, density $\rho, \beta$ and $\alpha$. In the case of P-FGC, $S$ is the power-law index. Allocating a zero value to $S$, the FGC reverts to a fully ceramic layer; when $S=\infty$ the core layer is fully metallic. Based on the two-fold definition of $J^{\mathcal{C}}(z)$ in Equation (5), the elasticity modulus varies in the FGC thickness as plotted in Figure 2.

The sandwich beam system includes two CNTRC faces, with increased overall stiffness. Both external skins are assumed to be completely bonded to the FGC without any possible interlayer slip. The presence of CNTs within the PMMA matrix plays an efficient role in the general improvement of the mechanical properties. Due to the high aspect ratio of CNTs, their bending and bundling within the matrix phase and clusters formation seem to be almost predictable. In this paper, we consider the effect of the CNTs' agglomeration on the overall mechanical response, based on an EMT scheme [26]. Based on this approach, the bulk modulus $K$ and shear modulus $G$ inside and outside the clusters can be defined as $[26,27]$ :

$$
\begin{gathered}
K_{i n}^{t, b}=\frac{3 K_{p}\left(\mu-V_{r} \eta+V_{r} \eta \alpha_{r}\right)+\left(\delta_{r}-3 K_{p} \alpha_{r}\right) V_{r} \eta}{3\left(\mu-V_{r} \eta+V_{r} \eta \alpha_{r}\right)}, \\
G_{i n}^{t, b}=\frac{2 G_{p}\left(\mu-V_{r} \eta+V_{r} \eta \beta_{r}\right)+\left(\eta_{r}-2 G_{p} \beta_{r}\right) V_{r} \eta}{2\left(\mu-V_{r} \eta+V_{r} \eta \beta_{r}\right)} \\
K_{o u t}^{t, b}=\frac{3 K_{p}\left((1-\mu)-V_{r}(1-\eta)+V_{r}(1-\eta) \alpha_{r}\right)+\left(\delta_{r}-3 K_{p} \alpha_{r}\right) V_{r}(1-\eta)}{3\left((1-\mu)-V_{r}(1-\eta)+V_{r}(1-\eta) \alpha_{r}\right)} \\
G_{o u t}^{t, b}=\frac{2 G_{p}\left((1-\mu)-V_{r}(1-\eta)+V_{r}(1-\eta) \beta_{r}\right)+\left(\eta_{r}-2 G_{p} \beta_{r}\right) V_{r}(1-\eta)}{2\left((1-\mu)-V_{r}(1-\eta)+V_{r}(1-\eta) \beta_{r}\right)}
\end{gathered}
$$

where subscripts $p$ and $r$ refer to the polymeric matrix and CNTs. 


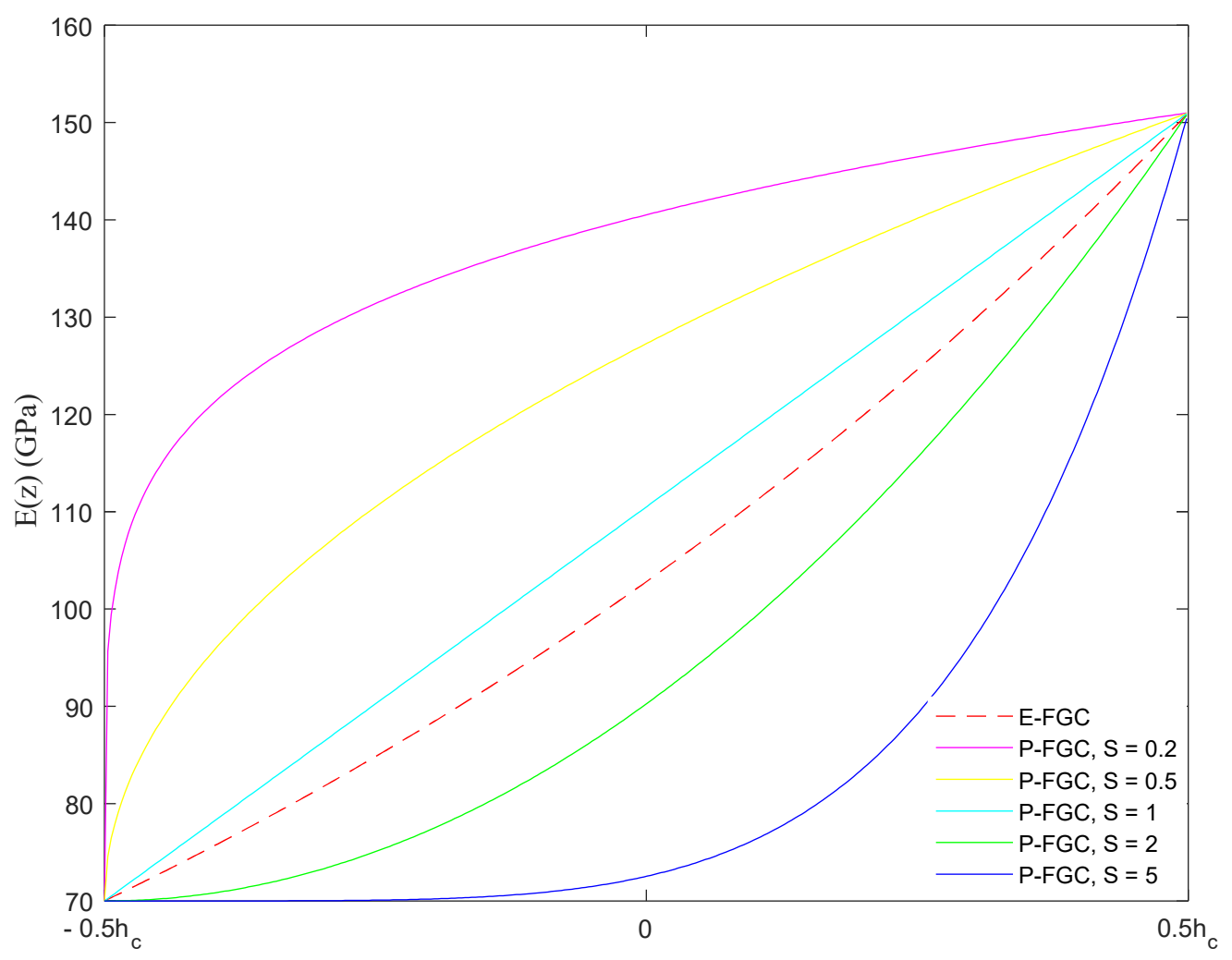

Figure 2. Variation of the elasticity modulus with the core thickness based on the E-FGC and P-FGC models.

Furthermore, $\mu$ and $\eta$ denote the CNTs' agglomeration region volume fraction and the cluster's CNTs' volume fraction. It should be mentioned that the value of $\mu$ can be lower or equal to $\eta$. Regarding the definition and value assumed by $\mu$ and $\eta$, some possible cases can occur, as detailed in Table 1.

Table 1. Possible combinations of $\mu$ and $\eta$.

\begin{tabular}{cc}
\hline Case & Result \\
\hline$\mu=0$ & No-agglomerated composite. \\
$\mu=1$ & The whole composite layer serves as a big agglomerated region. \\
$\eta=0$ & There is no CNT inside the clusters. \\
$\eta=1$ & All CNTs are agglomerated inside the clusters. \\
$\mu=\eta=1$ & Fully CNTs agglomerated composite. \\
\hline
\end{tabular}

In order to capture the impact of different CNT distribution patterns inside the composite faces, the following equations can be used to define the CNT volume fraction inside the composite skins [28]:

$$
V_{r}=\left\{\begin{array}{cc}
V^{*} & U \\
\frac{4}{h_{t, b}}\left|z \mp 0.5\left(h_{c}+h_{t, b}\right)\right| V^{*} & F G-X \\
\left(\frac{2 h_{t, b}-4}{h_{t, b}}\right)\left|z \mp 0.5\left(h_{c}+h_{t, b}\right)\right| V^{*} & F G-O \\
\left(\frac{h_{t, b}-2}{h_{t, b}}\right)\left(z \mp 0.5\left(h_{c}+h_{t, b}\right)\right) V^{*} & F G-A \\
\left(\frac{h_{t, b}+2}{h_{t, b}}\right)\left(z \mp 0.5\left(h_{c}+h_{t, b}\right)\right) V^{*} & F G-V
\end{array}\right.
$$

where $V^{*}$ refers to the weight fraction of CNTs. In Figure 3 we show the variation of the CNTs' volume fraction versus the composite layer thickness for different types of CNTs' 
distributions. Also, it should be mentioned that $V^{*}$ is the CNTs' volume fraction in the case of their uniform dispersion.

In addition, the terms $\alpha_{r}, \beta_{r}, \eta_{r}$ and $\delta_{r}$ can be written as follows [17]:

$$
\begin{gathered}
\alpha_{r}=\frac{3\left(K_{p}+G_{p}\right)+k_{r}-l_{r}}{3\left(G_{p}+k_{r}\right)}, \\
\beta_{r}=\frac{4 G_{p}+2 k_{r}+l_{r}}{15\left(G_{p}+k_{r}\right)}+\frac{4 G_{p}}{5\left(G_{p}+p_{r}\right)}+\frac{2\left(G_{p}\left(3 K_{p}+G_{p}\right)+G_{p}\left(3 K_{p}+7 G_{p}\right)\right)}{5 G_{p}\left(3 K_{p}+G_{p}\right)+5 m_{r}\left(3 K_{p}+7 G_{p}\right)} \\
\eta_{r}=\frac{2\left(n_{r}-l_{r}\right)}{15}+\frac{8\left(k_{r}-l_{r}\right)\left(2 G_{p}+l_{r}\right)}{15 K_{p}\left(G_{p}+m_{r}\right)+5 G_{p}\left(G_{p}+7 m_{r}\right)}+\frac{8 G_{p} p_{r}}{5\left(G_{p}+p_{r}\right)} \\
\delta_{r}=\frac{n_{r}+2 l_{r}}{3}+\frac{\left(2 k_{r}+l_{r}\right)\left(3 K_{p}+2 G_{p}-l_{r}\right)}{3\left(G_{p}+k_{r}\right)}
\end{gathered}
$$

where $k_{r}, l_{r}, m_{r}, p_{r}$ and $n_{r}$ denote the CNTs' elastic Hill's constants which are varied for different types of CNTs with respect to their chiral index value. In the current study, such constants are defined for single-walled carbon nanofillers (SWCNTs) with a chirality index equal to 10 [29].

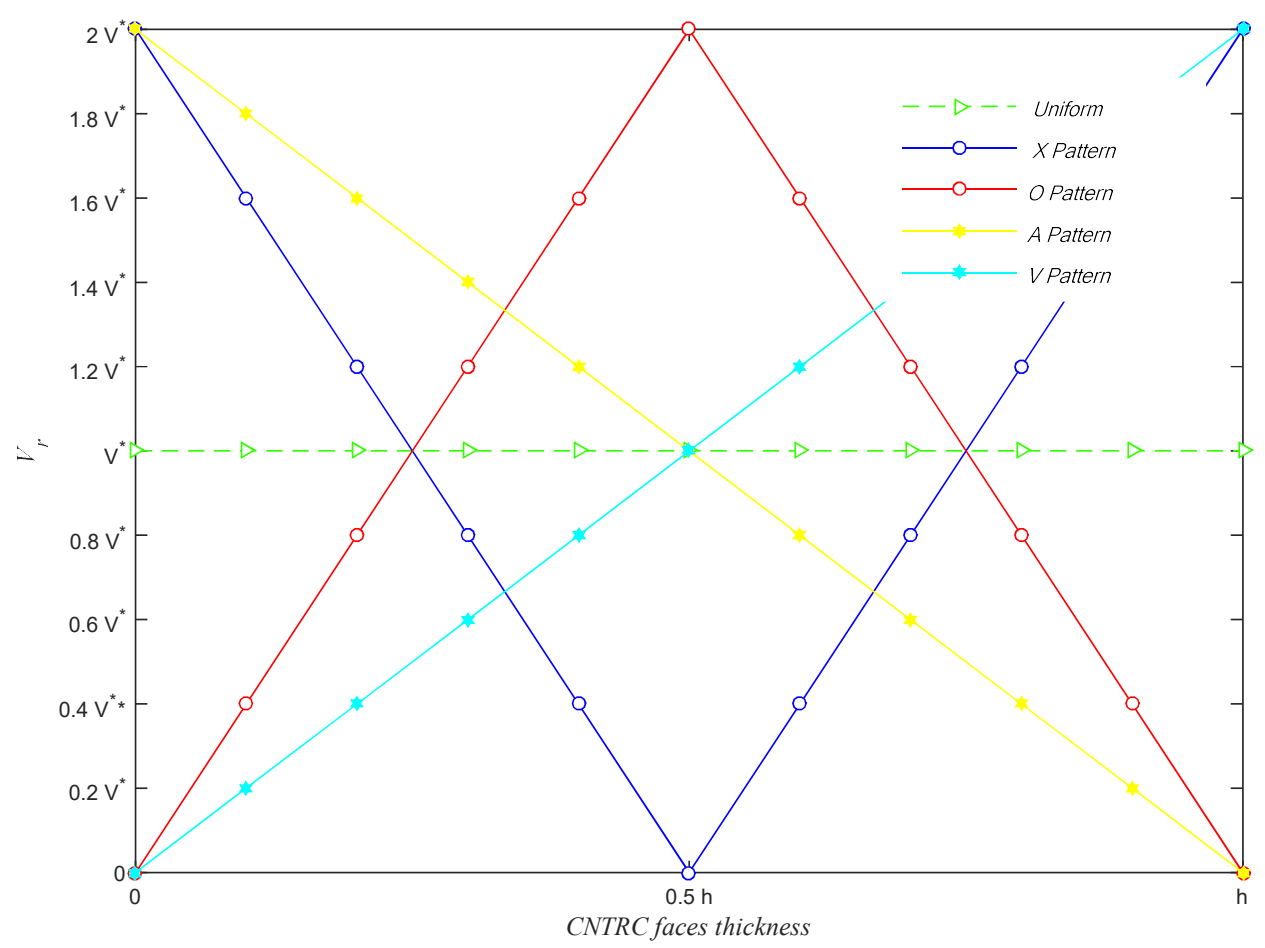

Figure 3. Variation of the CNTs' volume fraction versus the CNTRC skin thickness for different types of CNTs' patterns.

Thus, the bulk modulus and shear modulus of the external skins can be obtained as [30]:

$$
\begin{aligned}
& K_{n}^{t, b}(z)=K_{\text {out }}^{t, b}+\frac{\mu\left(K_{\text {in }}^{t, b}-K_{\text {out }}^{t, b}\right)}{1+P^{t, b}(1-\mu)\left(\frac{K_{\text {in }}^{t, b}-K_{\text {out }}^{t, b}}{K_{\text {out }}^{t, b}}\right)}, \\
& G_{n}^{t, b}(z)=G_{\text {out }}^{t, b}+\frac{\mu\left(G_{\text {in }}^{t, b}-G_{\text {out }}^{t, b}\right)}{1+I^{t, b}(1-\mu)\left(\frac{G_{\text {in }}^{t, b}-G_{\text {out }}^{t, b}}{G_{\text {out }}^{t, b}}\right)}
\end{aligned}
$$


in which subscript $n$ denotes the nanocomposite faces, and:

$$
\begin{aligned}
P^{t, b} & =\frac{1+v_{\text {out }}^{t, b}}{3\left(1-v_{\text {out }}^{t, b}\right)} \\
I^{t, b} & =\frac{8-10 v_{\text {out }}^{t, b}}{15\left(1-v_{\text {out }}^{t, b}\right)}
\end{aligned}
$$

where,

$$
v_{\text {out }}^{t, b}=\frac{3 K_{\text {out }}^{t, b}-2 G_{\text {out }}^{t, b}}{6 K_{\text {out }}^{t, b}+2 G_{\text {out }}^{t, b}}
$$

The mechanical properties of the composite faces including $E, v, \rho, \alpha$ and $\beta$ can be addressed as $[17,31]$ :

$$
\begin{gathered}
E^{t, b}(z)=9 K_{n}^{t, b} G_{n}^{t, b} /\left(3 K_{n}^{t, b}+G_{n}^{t, b}\right), \\
v^{t, b}(z)=\left(3 K_{n}^{t, b}-2 G_{n}^{t, b}\right) /\left(6 K_{n}^{t, b}+2 G_{n}^{t, b}\right), \\
\rho^{t, b}(z)=\left(\rho_{r}^{t, b}-\rho_{p}^{t, b}\right) V_{r}+\rho_{p}^{t, b}, \\
\alpha^{t, b}(z)=\left(\frac{E+4 v K_{n}(1+v)}{E+4 K_{n}(1+v)^{2}}\right)^{t, b}\left(\frac{V_{r} E_{11}^{C N T} \alpha_{11}^{C N T}+\left(1-V_{r}\right) E_{p} \alpha_{p}}{V_{r} E_{11}^{C N T}+\left(1-V_{r}\right) E_{p}}\right) \\
\beta^{t, b}(z)=\left(\frac{E+4 v K_{n}(1+v)}{E+4 K_{n}(1+v)^{2}}\right)^{t, b}\left(\frac{V_{r} E_{11}^{C N T} \beta_{11}^{C N T}+\left(1-V_{r}\right) E_{p} \beta_{p}}{V_{r} E_{11}^{C N T}+\left(1-V_{r}\right) E_{p}}\right)
\end{gathered}
$$

Finally, the elastic constants for the external layers can be defined as [32]:

$$
\begin{aligned}
& A_{11}^{c, t, b}(z)=\frac{E^{c, t, b}(z)}{1-\left(v^{c, t, b}(z)\right)^{2}} \\
& A_{55}^{c, t, b}(z)=\frac{E^{c, t, b}(z)}{2\left(1+v^{c, t, b}(z)\right)}
\end{aligned}
$$

\section{Governing Equations}

We now apply the virtual work principle to determine the governing equations of the problem [15]:

$$
\delta(\Omega-\Psi)=0
$$

where $\Omega$ is the strain energy and $\Psi$ is the external work.

The classical strain energy for a sandwich beam is defined as [33]:

$$
\Omega=\frac{1}{2} \int_{x} \int_{z}\left(\sigma_{x x} \varepsilon_{x}+\tau_{x z} \gamma_{x z}\right)^{c, t, b} d z d x
$$

The external work includes three terms, namely, the thermal force, the external force related to humidity and the elastic substrate force, defined as follows [34]:

$$
\begin{gathered}
F^{T}=\int_{z} A_{11}^{c, t, b} \alpha^{c, t, b} \Delta T d z, \\
F^{H}=\int_{z} A_{11}^{c, t, b} \beta^{c, t, b} \Delta H d z, \\
F^{f}=L_{1} w-L_{2} \frac{\partial^{2} w}{\partial x^{2}}
\end{gathered}
$$

where $L_{1}$ is the spring constant and $L_{2}$ stands for the shear layer constant. The total external work reads as follows [35]:

$$
\Psi=\frac{1}{2} \int_{x}\left(\left(F^{T}+F^{H}\right)\left(\frac{\partial w}{\partial x}\right)^{2}-F^{f} w\right) d x
$$


By substitution of Equations (26) and (28) into Equation (25), after mathematical manipulation, we obtain the following governing equations:

$$
\begin{gathered}
\delta u:-\frac{\partial}{\partial x}\left(A_{0} \frac{\partial u}{\partial x}-A_{1} \frac{\partial^{2} w}{\partial x^{2}}+A_{3} \frac{\partial u_{1}}{\partial x}\right)=0 \\
\delta u_{1}:-\frac{\partial}{\partial x}\left(A_{3} \frac{\partial u}{\partial x}+A_{4} \frac{\partial u_{1}}{\partial x}-A_{5} \frac{\partial^{2} w}{\partial x^{2}}\right)+A_{6} u_{1}=0 \\
\delta w:-\frac{\partial^{2}}{\partial x^{2}}\left(A_{1} \frac{\partial u}{\partial x}-A_{2} \frac{\partial^{2} w}{\partial x^{2}}+A_{5} \frac{\partial u_{1}}{\partial x}\right)-L_{2} \frac{\partial^{2} w}{\partial x^{2}}+L_{1} w-F^{T} \frac{\partial^{2} w}{\partial x^{2}}-F^{H} \frac{\partial^{2} w}{\partial x^{2}}=0
\end{gathered}
$$

where,

$$
\begin{gathered}
{\left[\begin{array}{c}
A_{0} \\
A_{1} \\
A_{2} \\
A_{3} \\
A_{4} \\
A_{5}
\end{array}\right]=\int_{z} A_{11}^{c, t, b}\left[\begin{array}{c}
1 \\
z \\
z^{2} \\
Q(z) \\
Q^{2}(z) \\
z Q(z)
\end{array}\right] d z} \\
A_{6}=\int_{z} A_{55}^{c, t, b}\left(\frac{\partial Q(z)}{\partial z}\right)^{2} d z
\end{gathered}
$$

\section{Analytical Solution Procedure}

Equations (29)-(31) are solved here analytically by means of a Navier-type procedure. Based on this technique, we use the following expressions to define the displacement components, which satisfy simply supported boundary conditions [36]:

$$
\begin{aligned}
u(x) & =\sum_{m=1}^{\infty} U \cos \left(\frac{m \pi}{a} x\right), \\
u_{1}(x) & =\sum_{m=1}^{\infty} U_{1} \cos \left(\frac{m \pi}{a} x\right), \\
w(x) & =\sum_{m=1}^{\infty} W \sin \left(\frac{m \pi}{a} x\right),
\end{aligned}
$$

where, $U, U_{1}$, and $W$ serve as unknown coefficients; $m$ denotes the mode number along the ESB length. By placing Equation (33) into Equations (29)-(31), after mathematical manipulation, the governing equations are easily solved.

\section{Numerical Results and Discussions}

In this section, we perform various numerical examples to demonstrate the accuracy of the formulation proposed herein, to study the critical buckling load of an Euler-Bernoulli beam (EBB) and Timoshenko beam (TB), for different values of power-law exponent and geometrical characteristics. Our results are compared to predictions by Li and Batra [37], as summarized in Table 2, with an acceptable agreement for the geometrical length-tothickness ratios $a / h=5$ and 10 , and for all values of $S$. This confirms the reliability of the proposed formulation to handle such a topic.

A systematic analysis is repeated, by assuming different input material and geometrical properties in the model, as listed in Tables 3-5, in line with Refs. [17,38], in which the term $N^{*}$ stands for the nondimensional critical buckling load. 
Table 2. Comparison of the dimensionless critical buckling load of FGM beams as computed in the current study with respect to the literature [37] $(\times 100)$.

\begin{tabular}{ccccccccc}
\hline & \multicolumn{3}{c}{$a / h=5$} & \multicolumn{3}{c}{$a / h=10$} \\
\cline { 2 - 8 } & \multicolumn{3}{c}{ EBB } & \multicolumn{2}{c}{ TB } & \multicolumn{2}{c}{ EBB } & \multicolumn{2}{c}{ TB } \\
\cline { 2 - 9 } & Ref. [37] & Present & Ref. [37] & Present & Ref. [37] & Present & Ref [37] & Present \\
\hline 0 & 0.535 & 0.566 & 0.488 & 0.521 & 0.535 & 0.566 & 0.523 & 0.554 \\
0.5 & 0.347 & 0.365 & 0.319 & 0.340 & 0.347 & 0.365 & 0.340 & 0.359 \\
1 & 0.267 & 0.282 & 0.246 & 0.263 & 0.267 & 0.282 & 0.261 & 0.277 \\
2 & 0.208 & 0.220 & 0.192 & 0.205 & 0.208 & 0.220 & 0.204 & 0.216 \\
5 & 0.176 & 0.186 & 0.160 & 0.171 & 0.176 & 0.186 & 0.171 & 0.182 \\
7 & 0.169 & 0.178 & 0.152 & 0.163 & 0.169 & 0.178 & 0.164 & 0.174 \\
10 & 0.160 & 0.169 & 0.144 & 0.154 & 0.160 & 0.169 & 0.156 & 0.165 \\
\hline
\end{tabular}

Table 3. FGC material properties [38].

\begin{tabular}{|c|c|c|c|c|c|c|}
\hline Material & $\rho\left(\mathrm{Kg} / \mathrm{m}^{3}\right)$ & $v$ & $E$ (GPa) & $\beta\left(10^{-3} / \mathrm{K}\right)$ & $\alpha\left(10^{-6 / K}\right)$ & $\theta\left(10^{-6} / \mathrm{K}\right)$ \\
\hline $\mathrm{Al}_{2} \mathrm{O}_{3}$ & 3800 & 0.3 & 380 & 1 & 8.3 & 8.3 \\
\hline $\mathrm{ZrO}_{2}$ & 3000 & 0.3 & 151 & 0 & 10 & 10 \\
\hline $\mathrm{Si}_{3} \mathrm{~N}_{4}$ & 2370 & 0.24 & 322.27 & 0 & 5.87 & 5.87 \\
\hline $\mathrm{Al}$ & 2707 & 0.3 & 70 & 440 & 24 & 24 \\
\hline
\end{tabular}

Table 4. CNTRC skin material properties [17].

\begin{tabular}{ccccccc}
\hline Material & $\rho\left(\mathbf{K g} / \mathbf{m}^{\mathbf{3}}\right)$ & $\boldsymbol{E}(\mathrm{GPa})$ & $\boldsymbol{\beta ( \mathbf { 1 0 } ^ { - \mathbf { 4 } } / \mathbf { K } )}$ & $\boldsymbol{\alpha ( \mathbf { 1 0 }} \mathbf{- 6} / \mathbf{K})$ & $K(\mathrm{GPa})$ & $\boldsymbol{G}(\mathrm{GPa})$ \\
\hline PMMA & 1150 & 2.5 & 20 & 45 & 2.6 & 0.93 \\
CNT & 1400 & 5646.6 & 3 & 3.45 & - & - \\
\hline
\end{tabular}

Table 5. Fundamental details of the model.

\begin{tabular}{ccccc}
\hline FGC Material & CNTRC Material & $\boldsymbol{h}_{\boldsymbol{c}}(\mathbf{m m})$ & $\boldsymbol{h}_{\boldsymbol{t}}=\boldsymbol{h}_{\boldsymbol{b}} \mathbf{( \mathbf { m m } )}$ & $\boldsymbol{a} \mathbf{( \mathbf { m m } )}$ \\
\hline $\mathrm{Al} \& \mathrm{ZrO}_{2}$ & CNTs \& PMMA & 5 & 2 & 30 \\
$N^{*}$ & $\mu$ & $\eta$ & $V^{*}$ & $s$ \\
$\frac{N a^{2}}{h_{c}^{3} E_{m}}$ & 0.3 & 0.4 & 0.2 & 2 \\
$H_{b}\left(\mathrm{wt} \% \mathrm{H}_{2} \mathrm{O}\right)$ & $T_{b}(\mathrm{~K})$ & $L_{1}\left(\mathrm{GN} / \mathrm{m}^{3}\right)$ & $L_{2}(\mathrm{KN} / \mathrm{m})$ & \\
0.1 & 300 & 5 & 50 & \\
\hline
\end{tabular}

In Figure 4, we plot the variation of the dimensionless critical buckling load $N^{*}$ vs. the CNTs' volume fraction inside clusters, $\eta$, while setting different combinations of the foundation parameters $L_{1}, L_{2}$.

Based on results in this figure, $\mathrm{CNTs}^{\prime}$ inflation inside some concentrated regions (i.e., an increased value $\eta$ ) yields a reduced critical buckling load because of the stiffness reduction in the whole structure, in line with the experimental findings by Pan et al. [11]. On the other hand, by increasing the foundation parameters $L_{1}, L_{2}$, the critical buckling load is enhanced because of an increased stiffness configuration induced on the structure.

As also plotted in Figure 5, the model is very sensitive to the rational length $a / h$ and to the CNTs' agglomeration region $\mu$, with a monotonic reduction of $N^{*}$ for an increased $a / h$ ratio, along with a gradual reduction of $N^{*}$ for a reduced level of $\mu$, under a fixed value of $a / h$. This means that a decreased agglomeration region of CNTs causes a stiffness reduction of the structure, which can buckle more easily. 


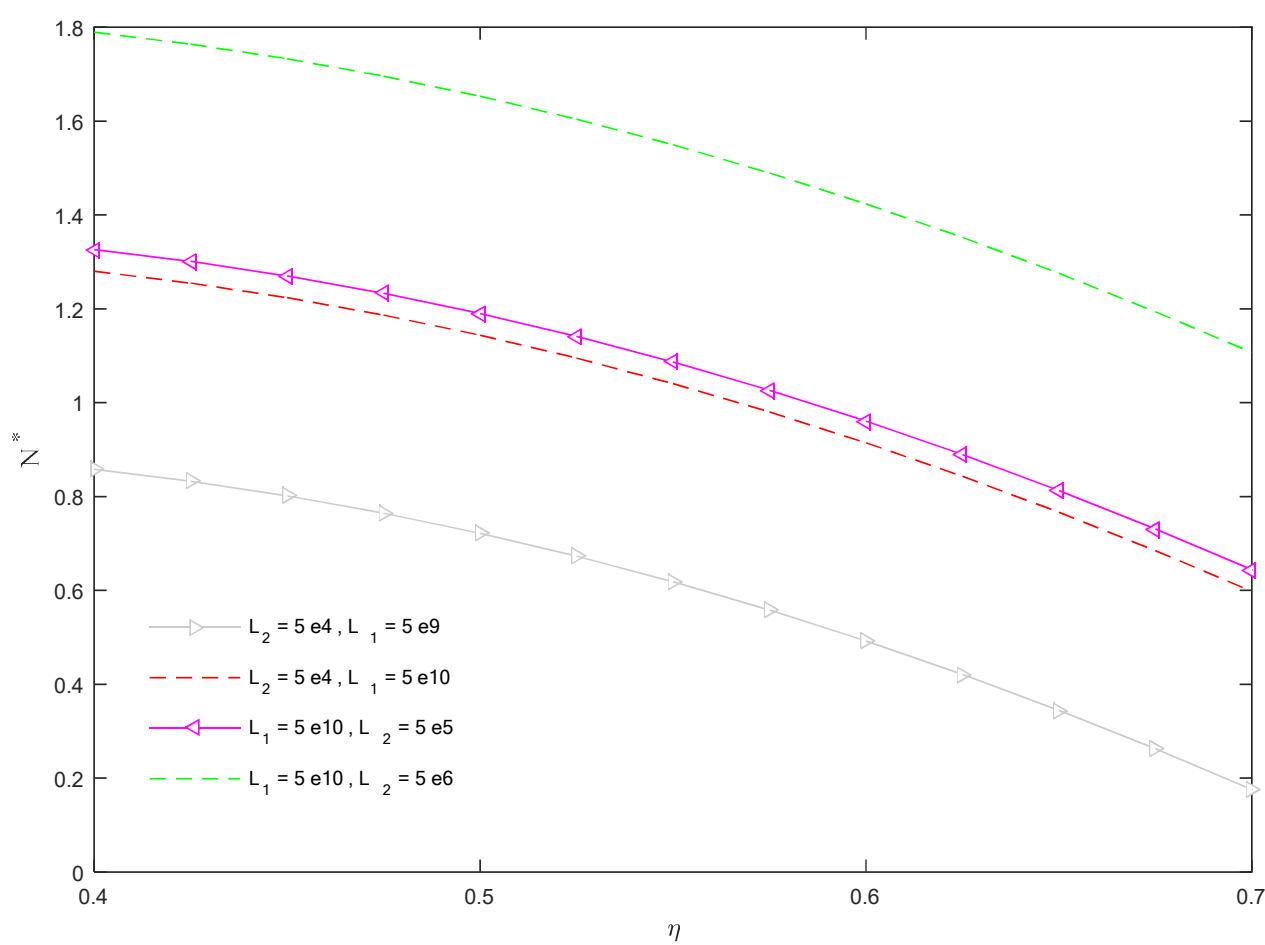

Figure 4. Dimensionless critical buckling load versus CNTs' volume fraction within clusters for different foundation parameters.

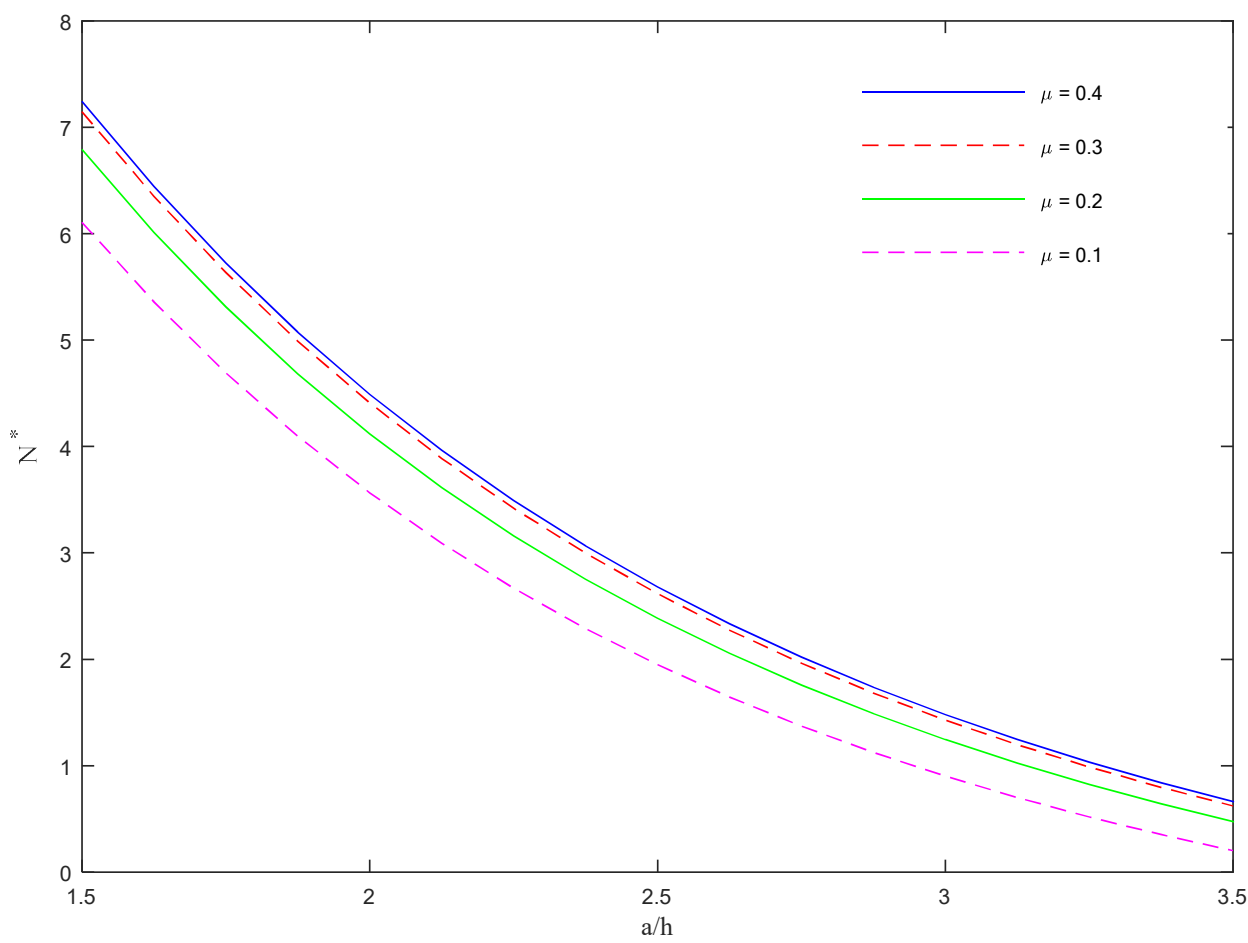

Figure 5. Dimensionless critical buckling load versus rational $a / h$ for different values of $\mu$.

The study considers the effect of different top-bottom moisture variations $\Delta \mathrm{H}_{\mathrm{tb}}$ based on the E\&P-FGC models, while varying the core thickness $h_{c}$, as represented in Figure 6. Based on the plots in Figure 6, it is visible that the application of a P-FGC model obtains higher values of the buckling load and structural stiffness compared to an E-FGC model, for a fixed value of $\Delta \mathrm{H}_{\mathrm{tb}}$. As also expected, an increased level of humidity in the surrounding environment has a destructive effect on the mechanical properties of the structure with 
a consecutive reduction of $N^{*}$ under the same assumption of $h_{c}$. This mechanical decay for different humidity conditions represents a key aspect for many aerospace and marine applications, as well as nanostructures like generators and sensors. At the same time, an increased core thickness makes the structure stiffer, thus leading to a monotonic increase in the buckling load for each selected model and moisture variation.

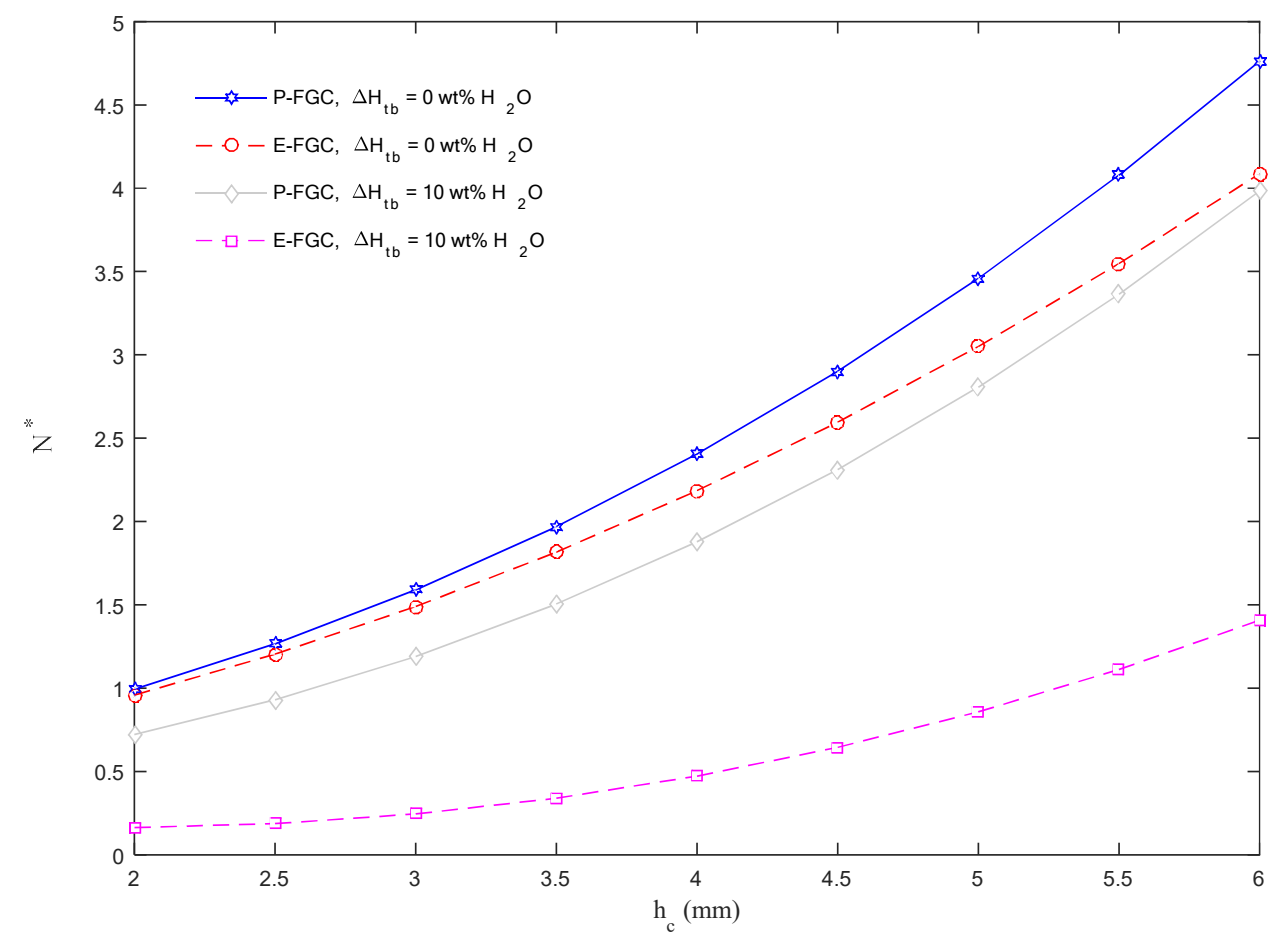

Figure 6. Dimensionless critical buckling load versus the core thickness for different moisture variations, based on E\&P-FGC models.

We now repeat a similar investigation based on the E\&P-FGC models, while checking for the sensitivity of the response to the thermal variation $\Delta T_{t b}$ among the top and bottom sides of the sandwich structure together with a varying thickness of the external skins (see Figure 7). Based on the plots in this figure, an increased thickness of the top and bottom sides enhances the overall stiffness of the structure together with its buckling load, independently of the selected model and thermal variation. Moreover, for each selected model, the results are almost unaffected by the thermal variation $\Delta T_{t b}$, where a P-FGC model always obtains higher values of the buckling load with respect to an E-FGC model.

Figure 8, instead, aims at evaluating the sensitivity of $N^{*}$ for different CNT volume fractions $V^{*}$ and different FGC material constituents. The monotonic increase in each curve for an increased level of $V^{*}$ demonstrates the beneficial effect of such a quantity on the overall buckling response of the structure. It was also found that the use of the $\mathrm{Al}$ in conjunction with $\mathrm{Al}_{2} \mathrm{O}_{3}, \mathrm{Si}_{3} \mathrm{~N}_{4}$ and $\mathrm{ZrO}_{2}$ as FGC material constituents, obtains higher magnitudes of the buckling load.

As visible in Figure 9, an enhanced power-law index causes a general reduction of dimensionless critical buckling. Among different possibilities of the CNTs' distributions, the FGA-V and FGV-A distributions yield the lowest and highest magnitudes of the buckling load, respectively, where other types of distribution yield intermediate predictions.

Figure 10 displays the critical buckling temperature against the volume fraction of CNTs for different CNTs' volume fractions, $\eta$. As visible in this figure, an increased value of $V^{*}$ improves the critical buckling temperature, especially for a reduced level of $\eta$. 


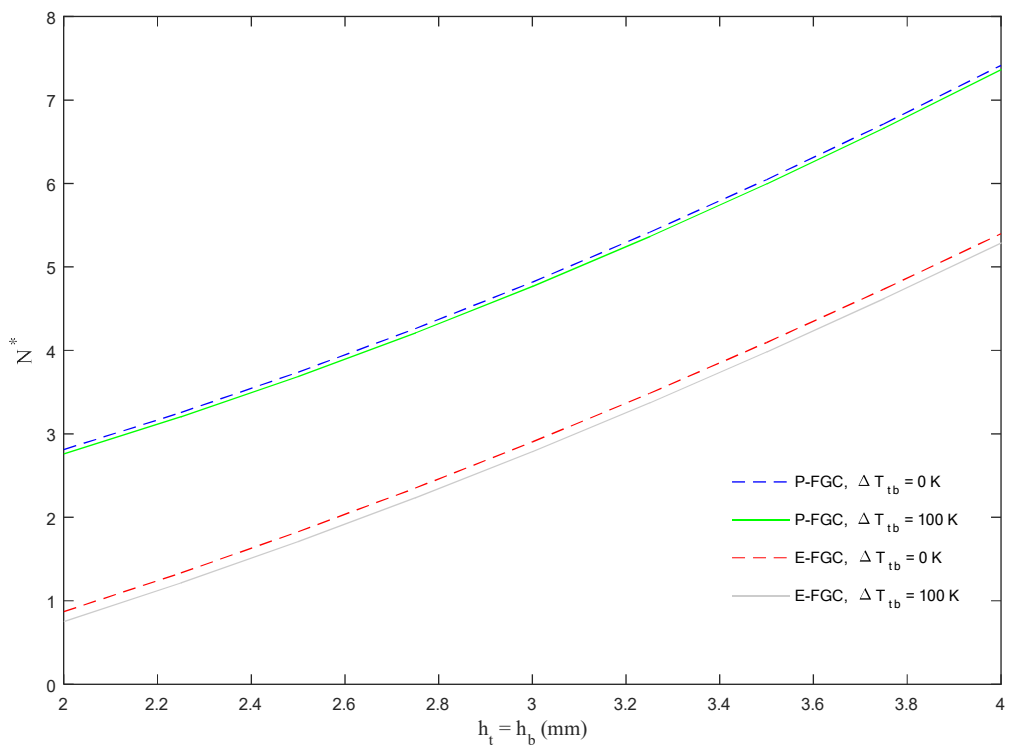

Figure 7. Dimensionless critical buckling load versus skin thickness for different thermal variations, based on E\&P-FGC models.

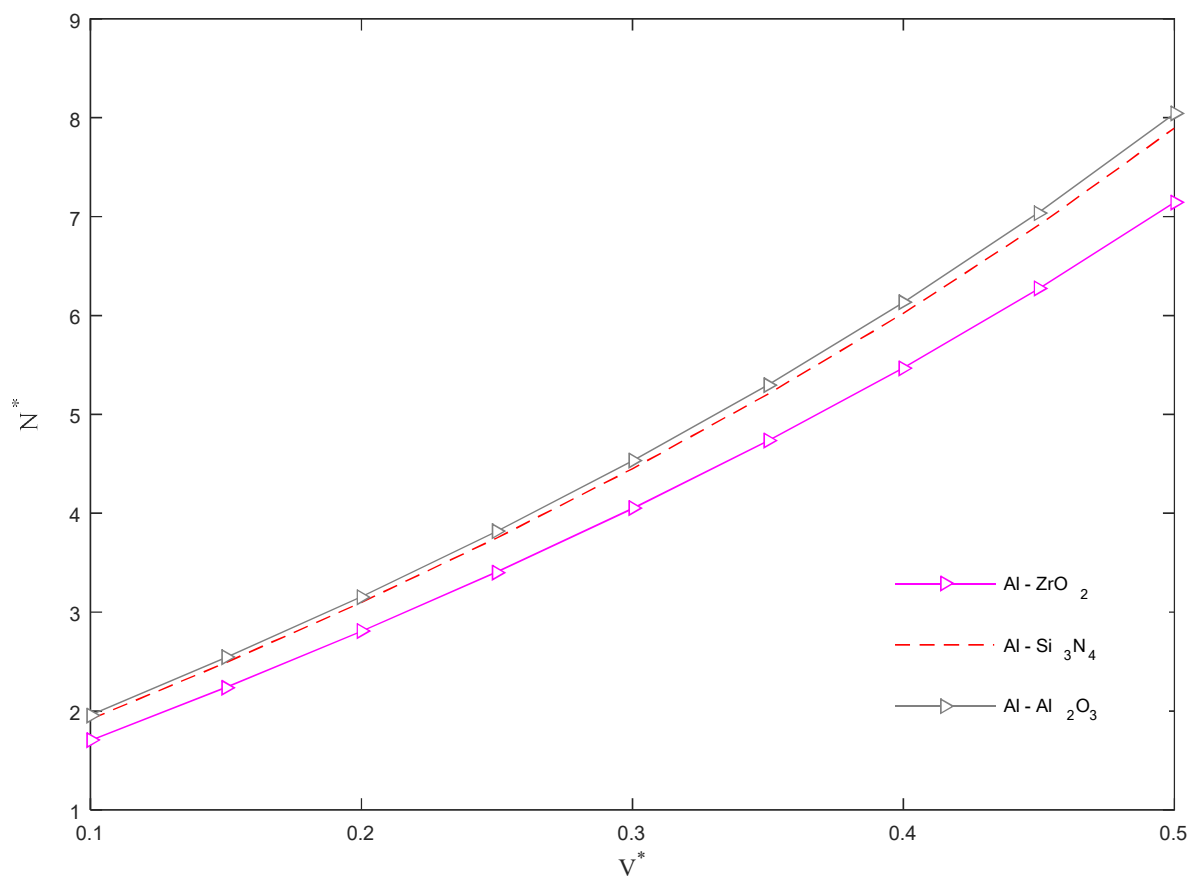

Figure 8. Dimensionless critical buckling load versus CNT volume fraction for different FGC material constituents. 


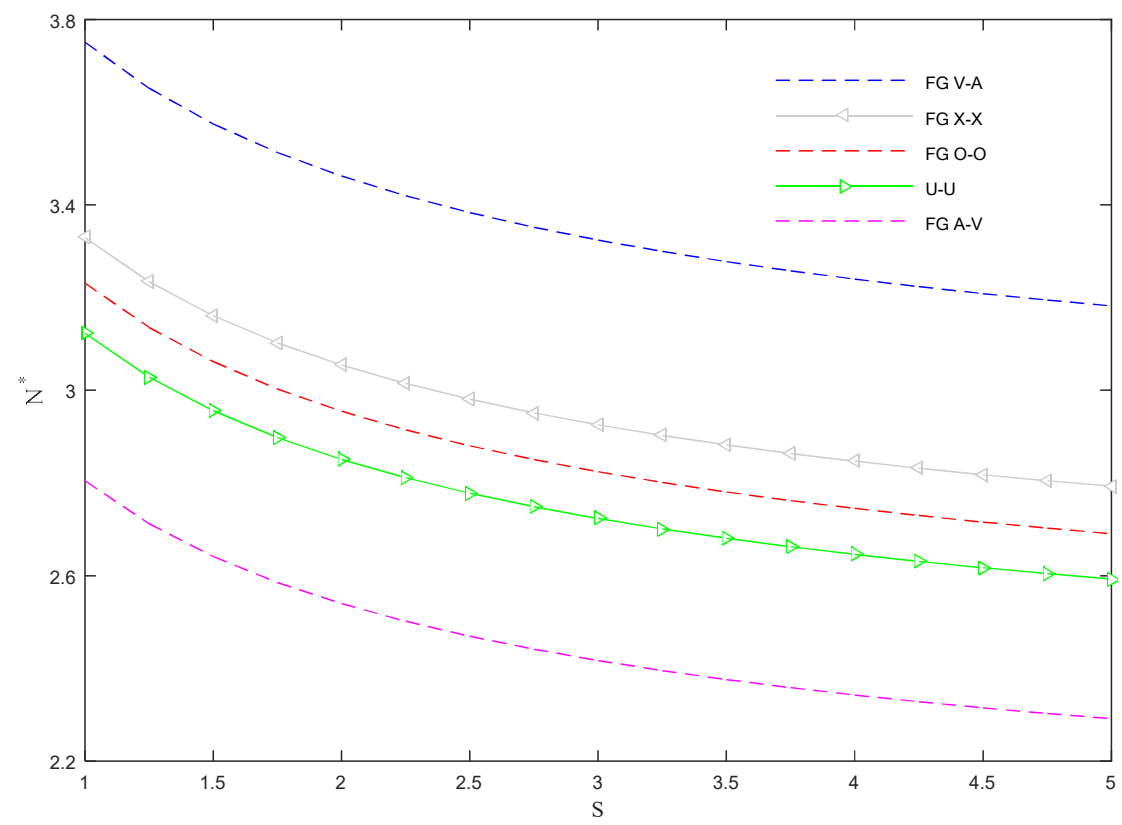

Figure 9. Dimensionless critical buckling load versus power-law index for different CNTs' distribution patterns within the CNTRC skins.

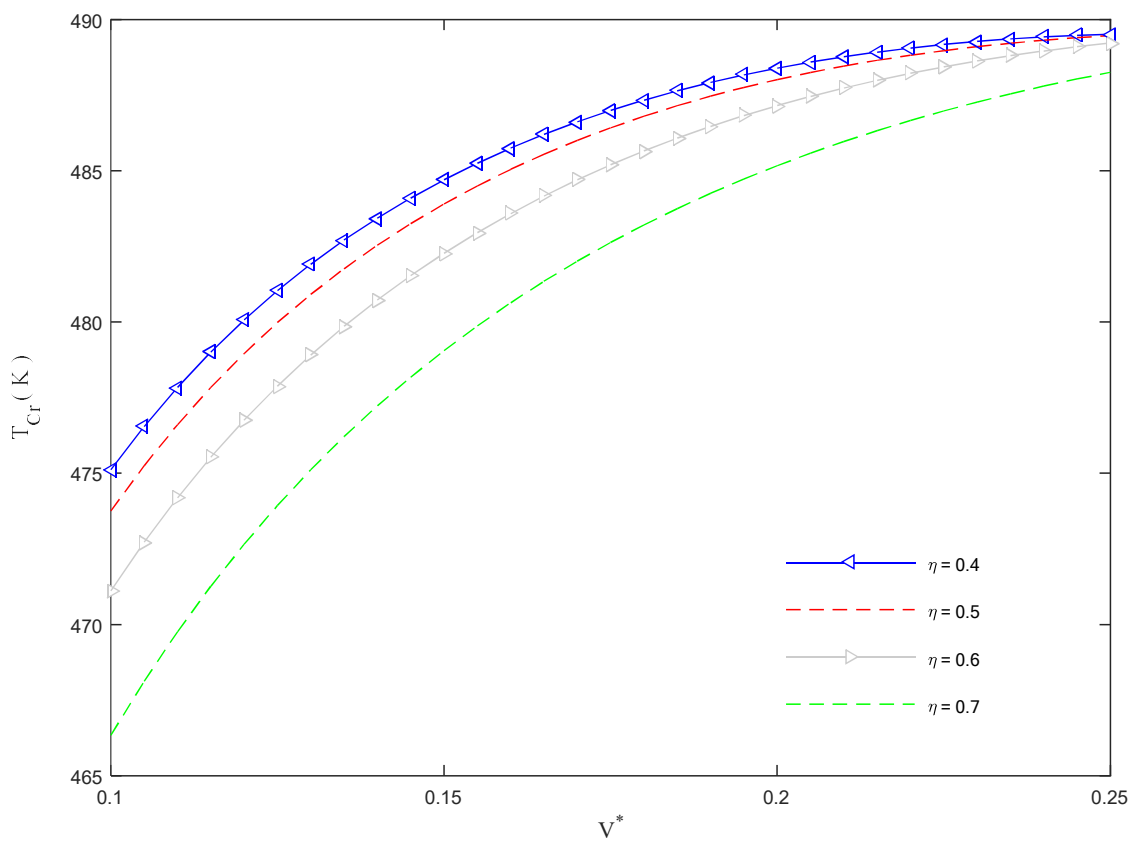

Figure 10. Critical buckling temperature versus CNTs' volume fractions for different values of CNTs' volume fractions inside the clusters.

At the same time, the critical buckling temperature seems to reduce for an increased length of the beam, as plotted in Figure 11, for different values of the power-law index $S$. Moreover, the overall thermal response of the structure, seems to be slightly affected by $S$, whose increase produces a meaningless reduction in $T_{c r}$ under the same geometrical length. 


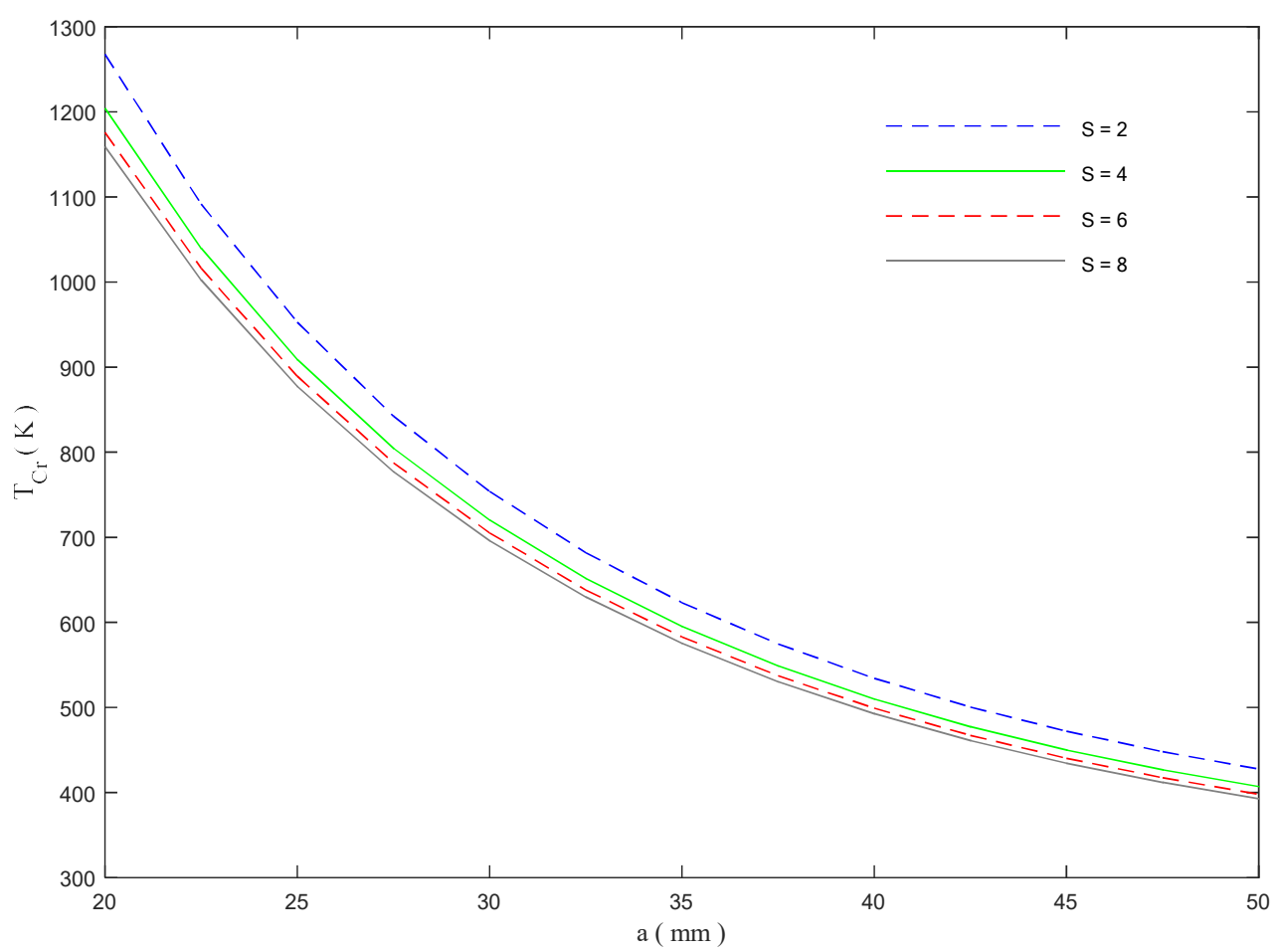

Figure 11. Critical buckling temperature versus the beam length, for different power-law indexes.

The final 3D plot in Figure 12 shows the double variation of $T_{c r}$ with the core thickness $h_{c}$ and substrate elastic constant $\mathrm{L}_{1}$. Note that the double increase in $\mathrm{h}_{\mathrm{c}}$ and $\mathrm{L}_{1}$ produce the highest value of $T_{c}$. The opposite effect is obtained for a simultaneous decrease in both parameters, which corresponds to the most serious thermal buckling condition.

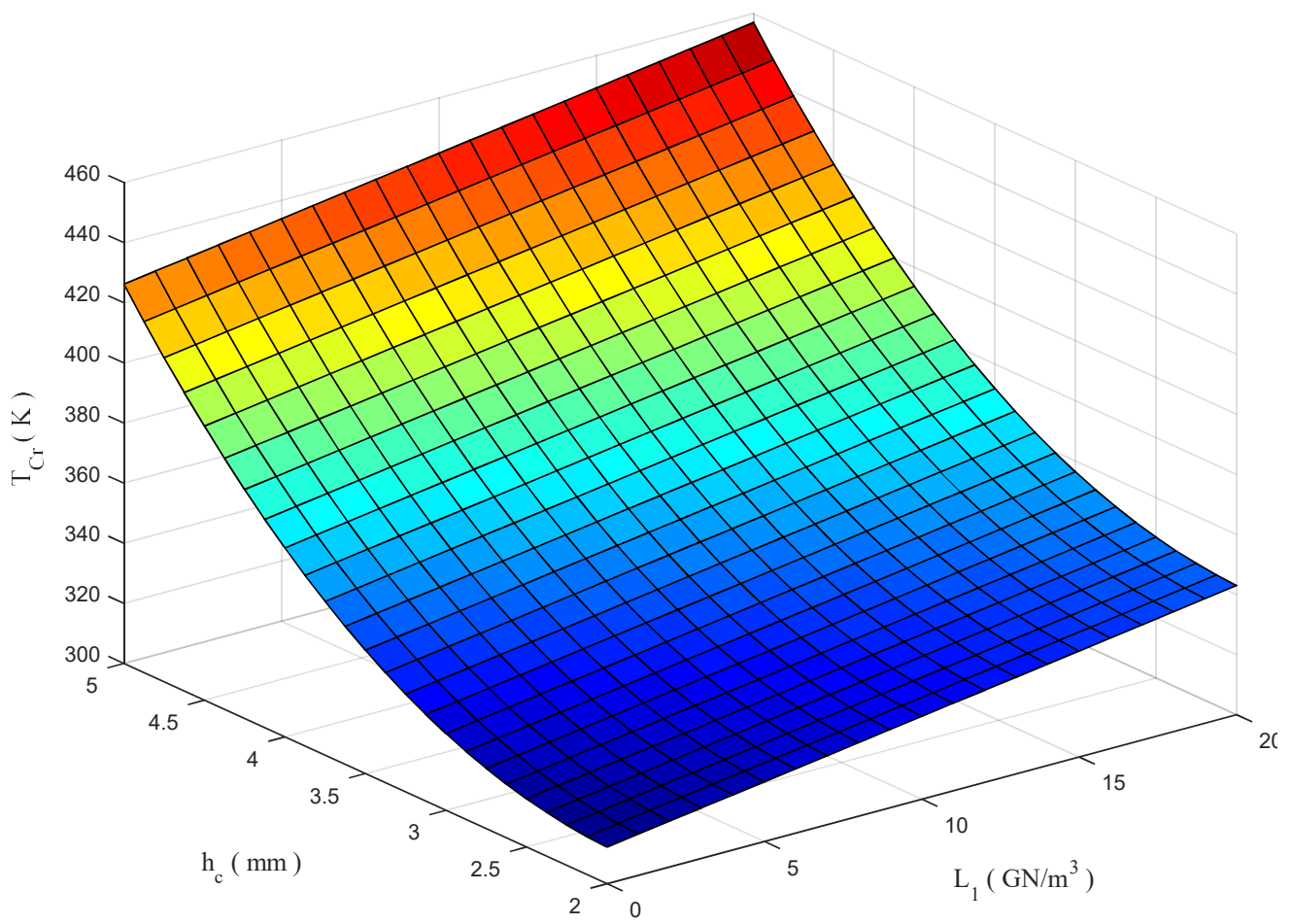

Figure 12. Double effect of core thickness and foundation spring parameter on the critical buckling temperature of a sandwich beam. 
Finally, in Table 6, we summarize the impact of different beam theories on the dimensionless critical buckling load, while considering different FGC models and CNT volume fractions, in a numerical sense. It seems that TSDT and HSDT provide the highest and lowest predictions, respectively, whereas SSDT and ESDT always produce intermediate results. It is also found that P-FGC-based results are much higher than those stemming from an E-FGC model, for a fixed value of $\mu$. Furthermore, a gradual increase in the buckling load is observed for an increased value of $\mu$, independent of the selected model.

Table 6. Dimensionless critical bucking load for different beam theories, FGC model and CNTs' volume fractions $\mu$.

\begin{tabular}{ccccccc}
\hline \multirow{2}{*}{ Theory } & \multicolumn{3}{c}{ E-FGC } & \multicolumn{3}{c}{ P-FGC } \\
\cline { 2 - 7 } & $\boldsymbol{\mu}=\mathbf{0 . 1}$ & $\boldsymbol{\mu}=\mathbf{0 . 2}$ & $\boldsymbol{\mu}=\mathbf{0 . 3}$ & $\boldsymbol{\mu}=\mathbf{0 . 1}$ & $\boldsymbol{\mu}=\mathbf{0 . 2}$ & $\boldsymbol{\mu}=\mathbf{0 . 3}$ \\
\hline HSDT & 0.3981 & 0.6916 & 0.8487 & 2.3511 & 2.6438 & 2.8015 \\
SSDT & 0.4017 & 0.6957 & 0.8528 & 2.3527 & 2.6458 & 2.8036 \\
ESDT & 0.4059 & 0.7005 & 0.8579 & 2.3547 & 2.4684 & 2.8064 \\
TSDT & 0.4163 & 0.7237 & 0.8897 & 2.3685 & 2.6702 & 2.8336 \\
\hline
\end{tabular}

\section{Conclusions}

This paper presents a thermomechanical buckling analysis of sandwich beams with two identical CNTRC skins, under different hygrothermal environmental conditions and elastic foundation parameters, based on an E\&P-FGC model. Different FGM theories are employed here in a unified framework for the first time, in conjunction with different $\mathrm{CNTs}^{\prime}$ agglomeration assumptions. By using the virtual displacement approach and Navier-type solution, we determine and solve the governing equations of the problem. Based on a large systematic investigation aimed at determining the thermomechanical buckling response and its sensitivity under different input parameters, some considerable conclusions can be summarized, as follows:

(a) The use of a P-FGC model obtains a higher stiffness and buckling load with respect to an E-FGC model.

(b) The presence of clusters or CNTs' concentrated regions has a beneficial effect on the mechanical behavior of such models.

(c) TSDT and HSDT provide the highest and lowest values of dimensionless critical buckling load, respectively, where SSDT and ESDT always produce intermediate results.

(d) The presence of a hygrothermal environment delivers lower levels of stiffness and critical buckling load on the system, whose results appear reasonable and consistent from a physical standpoint.

Author Contributions: Conceptualization, M.K., L.L., R.D. and F.T.; Formal analysis, M.K., L.L., R.D. and F.T.; Investigation, M.K. and L.L.; Validation, M.K., L.L., R.D. and F.T.; Writing-Original Draft, M.K., L.L., R.D. and F.T.; Writing-Review \& Editing, R.D. and F.T.; Supervision, R.D. and F.T. All authors have read and agreed to the published version of the manuscript.

Funding: This research received no external funding.

Data Availability Statement: Not applicable.

Conflicts of Interest: The authors declare no conflict of interest.

\section{References}

1. Shen, M.; Bever, M.B. Gradients in polymeric materials. J. Mater. Sci. 1972, 7, 741-746. [CrossRef]

2. Niino, M.; Hirai, T.; Watanabe, R. Functionally gradient materials. In pursuit of super heat resisting materials for spacecraft. $J$. Jpn. Soc. Compos. Mater. 1987, 13, 257-264. [CrossRef]

3. Fu, T.; Wu, X.; Xiao, Z.; Chen, Z. Thermoacoustic response of porous FGM cylindrical shell surround by elastic foundation subjected to nonlinear thermal loading. Thin-Walled Struct. 2020, 156, 106996. [CrossRef] 
4. Duc, N.D.; Cong, P.H. Nonlinear vibration of thick FGM plates on elastic foundation subjected to thermal and mechanical loads using the first-order shear deformation plate theory. Cogent Eng. 2015, 2. [CrossRef]

5. Shen, H.-S. A comparison of buckling and postbuckling behavior of FGM plates with piezoelectric fiber reinforced composite actuators. Compos. Struct. 2009, 91, 375-384. [CrossRef]

6. Zenkour, A. Hygro-thermo-mechanical effects on FGM plates resting on elastic foundations. Compos. Struct. 2010, 93, 234-238. [CrossRef]

7. Phung-Van, P.; Thai, C.H.; Ferreira, A.; Rabczuk, T. Isogeometric nonlinear transient analysis of porous FGM plates subjected to hygro-thermo-mechanical loads. Thin-Walled Struct. 2020, 148, 106497. [CrossRef]

8. Kiani, Y.; Eslami, M.R. Thermal buckling and post-buckling response of imperfect temperature-dependent sandwich FGM plates resting on elastic foundation. Arch. Appl. Mech. 2012, 82, 891-905. [CrossRef]

9. Jakkamputi, L.P.; Rajamohan, V. Dynamic characterization of CNT-reinforced hybrid polymer composite beam under elevated temperature-An experimental study. Polym. Compos. 2017, 40, 464-470. [CrossRef]

10. Kundalwal, S.I.; Rathi, A. Improved mechanical and viscoelastic properties of CNT-composites fabricated using an innovative ultrasonic dual mixing technique. J. Mech. Behav. Mater. 2020, 29, 77-85. [CrossRef]

11. Pan, S.; Dai, Q.; Safaei, B.; Qin, Z.; Chu, F. Damping characteristics of carbon nanotube reinforced epoxy nanocomposite beams. Thin-Walled Struct. 2021, 166, 108127. [CrossRef]

12. Fattahi, A.M.; Safaei, B.; Qin, Z.; Chu, F. Experimental studies on elastic properties of high density polyethylene-multi walled car-bon nanotube nanocomposites. Steel Compos. Struct. 2021, 38, 177-178. [CrossRef]

13. Arshid, E.; Amir, S.; Loghman, A. Static and dynamic analyses of FG-GNPs reinforced porous nanocomposite annular micro-plates based on MSGT. Int. J. Mech. Sci. 2020, 180, 105656. [CrossRef]

14. Foroutan, K.; Carrera, E.; Ahmadi, H. Nonlinear hygrothermal vibration and buckling analysis of imperfect FG-CNTRC cylindrical panels embedded in viscoelastic foundations. Eur. J. Mech.-A/Solids 2021, 85, 104107. [CrossRef]

15. Arshid, H.; Khorasani, M.; Soleimani-Javid, Z.; Dimitri, R.; Tornabene, F. Quasi-3D Hyperbolic Shear Deformation Theory for the Free Vibration Study of Honeycomb Microplates with Graphene Nanoplatelets-Reinforced Epoxy Skins. Molecules 2020, $25,5085$. [CrossRef]

16. Safaei, B. The effect of embedding a porous core on the free vibration behavior of laminated composite plates. Steel Compos. Struct. 2020, 35, 659-670.

17. Moradi-Dastjerdi, R.; Behdinan, K.; Safaei, B.; Qin, Z. Buckling behavior of porous CNT-reinforced plates integrated between active piezoelectric layers. Eng. Struct. 2020, 222, 111141. [CrossRef]

18. Kamarian, S.; Shakeri, M.; Yas, M.; Bodaghi, M.; Pourasghar, A. Free vibration analysis of functionally graded nanocomposite sandwich beams resting on Pasternak foundation by considering the agglomeration effect of CNTs. J. Sandw. Struct. Mater. 2015, 17, 632-665. [CrossRef]

19. Dabbagh, A.; Rastgoo, A.; Ebrahimi, F. Static stability analysis of agglomerated multi-scale hybrid nanocomposites via a refined theory. Eng. Comput. 2020, 37, 2225-2244. [CrossRef]

20. Khorasani, M.; Soleimani-Javid, Z.; Arshid, E.; Lampani, L.; Civalek, Ö. Thermo-elastic buckling of honeycomb micro plates integrated with FG-GNPs reinforced Epoxy skins with stretching effect. Compos. Struct. 2021, 258, 113430. [CrossRef]

21. Batou, B.; Nebab, M.; Bennai, R.; Atmane, H.A.; Tounsi, A.; Bouremana, M. Wave dispersion properties in imperfect sigmoid plates using various HSDTs. Steel Compos. Struct. 2019, 33, 699-716. [CrossRef]

22. Amir, S.; Khorasani, M.; BabaAkbar-Zarei, H. Buckling analysis of nanocomposite sandwich plates with piezoelectric face sheets based on flexoelectricity and first-order shear deformation theory. J. Sandw. Struct. Mater. 2018, 22, 2186-2209. [CrossRef]

23. Arshid, E.; Amir, S.; Loghman, A. Bending and buckling behaviors of heterogeneous temperature-dependent micro annular/circular porous sandwich plates integrated by FGPEM nano-Composite layers. J. Sandw. Struct. Mater. 2020, 1099636220955027. [CrossRef]

24. Khorasani, M.; Eyvazian, A.; Karbon, M.; Tounsi, A.; Lampani, L.; Sebaey, T.A. Magneto-electro-elastic vibration analysis of modified couple stress-based three-layered micro rectangular plates exposed to multi-physical fields considering the flexoelectricity effects. Smart Struct. Syst. 2020, 26, 331-343. [CrossRef]

25. Tang, Y.; Ding, Q. Nonlinear vibration analysis of a bi-directional functionally graded beam under hygro-thermal loads. Compos. Struct. 2019, 225, 111076. [CrossRef]

26. Khorasani, M.; Elahi, H.; Eugeni, M.; Lampani, L.; Civalek, O. Vibration of FG Porous Three-Layered Beams Equipped by Agglomerated Nanocomposite Patches Resting on Vlasov's Foundation. Transp. Porous Media 2021, 1-30. [CrossRef]

27. Moradi-Dastjerdi, R.; Behdinan, K.; Safaei, B.; Qin, Z. Static performance of agglomerated CNT-reinforced porous plates bonded with piezoceramic faces. Int. J. Mech. Sci. 2020, 188, 105966. [CrossRef]

28. Amir, S.; Soleimani-Javid, Z.; Arshid, E. Size-dependent free vibration of sandwich micro beam with porous core subjected to thermal load based on SSDBT. ZAMM 2019, 99, e201800334. [CrossRef]

29. Fantuzzi, N.; Tornabene, F.; Bacciocchi, M.; Dimitri, R. Free vibration analysis of arbitrarily shaped Functionally Graded Carbon Nanotube-reinforced plates. Compos. Part B Eng. 2017, 115, 384-408. [CrossRef]

30. Dabbagh, A.; Rastgoo, A.; Ebrahimi, F. Thermal buckling analysis of agglomerated multiscale hybrid nanocomposites via a refined beam theory. Mech. Based Des. Struct. Mach. 2021, 49, 403-429. [CrossRef] 
31. Kamarian, S.; Salim, M.; Dimitri, R.; Tornabene, F. Free vibration analysis of conical shells reinforced with agglomerated Carbon Nanotubes. Int. J. Mech. Sci. 2016, 108-109, 157-165. [CrossRef]

32. Zhang, L.; Lai, S.; Wang, C.; Yang, J. DSC regularized Dirac-delta method for dynamic analysis of FG graphene platelet-reinforced porous beams on elastic foundation under a moving load. Compos. Struct. 2021, 255, 112865. [CrossRef]

33. Eyvazian, A.; Hamouda, A.M.; Tarlochan, F.; Mohsenizadeh, S.; Dastjerdi, A.A. Damping and vibration response of viscoelastic smart sandwich plate reinforced with non-uniform Graphene platelet with magnetorheological fluid core. Steel Compos. Struct. 2019, 33, 891-906.

34. Arshid, E.; Khorasani, M.; Soleimani-Javid, Z.; Amir, S.; Tounsi, A. Porosity-dependent vibration analysis of FG microplates embedded by polymeric nanocomposite patches considering hygrothermal effect via an innovative plate theory. Eng. Comput. 2021, 1-22. [CrossRef]

35. Arshid, E.; Kiani, A.; Amir, S. Magneto-electro-elastic vibration of moderately thick FG annular plates subjected to multi physical loads in thermal environment using GDQ method by considering neutral surface. Proc. Inst. Mech. Eng. Part L J. Mater. Des. Appl. 2019, 233, 2140-2159. [CrossRef]

36. Arshid, E.; Kiani, A.; Amir, S.; Dehaghani, M.Z. Asymmetric free vibration analysis of first-order shear deformable functionally graded magneto-electro-thermo-elastic circular plates. Proc. Inst. Mech. Eng. Part C J. Mech. Eng. Sci. 2019, 233, 5659-5675. [CrossRef]

37. Li, S.-R.; Batra, R.C. Relations between buckling loads of functionally graded Timoshenko and homogeneous Euler-Bernoulli beams. Compos. Struct. 2013, 95, 5-9. [CrossRef]

38. Sharma, A.; Sharma, P.; Chauhan, P.S.; Bhadoria, S. Study on Harmonic Analysis of Functionally Graded Plates Using Fem. Int. J. Appl. Mech. Eng. 2018, 23, 941-961. [CrossRef]

39. Eyvazian, A.; Moeinifard, M.; Musharavati, F.; Taghizadeh, S.A.; Mahdi, E.; Hamouda, A.M.; Tran, T.N. Mechanical behavior of resin pin-reinforced composite sandwich panels under quasi-static indentation and three-point bending loading conditions. $J$. Sandw. Struct. Mater. 2021, 23, 2127-2145. [CrossRef]

40. Feng, P.; Chang, H.; Liu, X.; Ye, S.; Shu, X.; Ran, Q. The significance of dispersion of nano-SiO2 on early age hydration of cement pastes. Mater. Des. 2020, 186, 108320. [CrossRef]

41. Soleimani-Javid, Z.; Arshid, E.; Khorasani, M.; Amir, S.; Tounsi, A. Size-dependent flexoelectricity-based vibration characteristics of honeycomb sandwich plates with various boundary conditions. Adv. Nano Res. 2021, 10, 449-460.

42. Li, X.; Yang, H.; Zhang, J.; Qian, G.; Yu, H.; Cai, J. Time-Domain Analysis of Tamper Displacement during Dynamic Compaction Based on Automatic Control. Coatings 2021, 11, 1092. [CrossRef]

43. Kargar, S.; Baniamerianb, Z.; Mehdipourb, R. Desalination Using Nanoporous Graphene; International Conference of Nanostructures, Institute for Nanoscience \& Nanotechnology (INST), Sharif University of Technology: Tehran, Iran, 2020; pp. 678-680.

44. Hu, L.-B.; Huang, X.-Y.; Zhang, S.; Chen, X.; Dong, X.-H.; Jin, H.; Jiang, Z.-Y.; Gong, X.-R.; Xie, Y.-X.; Li, C.; et al. MoO3 structures transition from nanoflowers to nanorods and their sensing performances. J. Mater. Sci. Mater. Electron. 2021, 32, 23728-23736. [CrossRef]

45. Amir, S.; BabaAkbar-Zarei, H.; Khorasani, M. Flexoelectric vibration analysis of nanocomposite sandwich plates. Mech. Based Des. Struct. Mach. 2019, 48, 146-163. [CrossRef]

46. Li, Y.; Macdonald, D.D.; Yang, J.; Qiu, J.; Wang, S. Point defect model for the corrosion of steels in supercritical water: Part I, film growth kinetics. Corros. Sci. 2020, 163, 108280. [CrossRef]

47. Khorasani, M.; Soleimani-Javid, Z.; Arshid, E.; Amir, S.; Civalek, Ö. Vibration analysis of graphene nanoplatelets' reinforced composite plates integrated by piezo-electromagnetic patches on the piezo-electromagnetic media. Waves Random Complex Media 2021, 1-31. [CrossRef]

48. Eyvazian, A.; Zhang, C.; Musharavati, F.; Khan, A.; Sebaey, T.A. Forced resonance vibration analysis in advanced polymeric nanocomposite plate surrounded by an elastic medium. Compos. Struct. 2021, 275, 114389. [CrossRef]

49. Mou, B.; Bai, Y. Experimental investigation on shear behavior of steel beam-to-CFST column connections with irregular panel zone. Eng. Struct. 2018, 168, 487-504. [CrossRef] 